\title{
Taller "la persona del terapeuta": Una experiencia de formación que promueve el aprendizaje
}

\author{
Ana Margarita Maida Sosic, María Elisa Molina Pavez, María Teresa del Río Albornoz. \\ Unidad de Terapia Familiar, Departamento de Pediatría, Campus Oriente, Universidad de Chile, Hospital Luis Calvo \\ Mackenna.
}

Introducción: El ar tículo describe las actividades realizadas en un taller centrado en la persona del terapeuta con el fin de desarrollar habilidades de relación interpersonal que surgen y afectan el trabajo terapéutico. Este se lleva a cabo como parte de un programa de entrenamiento de alumnos de Psicología y becados de Psiquiatría en un hospital pediátrico. Metodología: Se trabaja con los postulados teóricos del construccionismo social, enfoque que integra las ideas del pensamiento post moderno a las ciencias sociales y a la práctica clínica. En este ar tículo se expone brevemente algunas de sus principales premisas, las cuales son objeto de estudio en una instancia paralela. En el taller se utiliza una metodología experiencial e interactiva para revisar aspectos personales, rol profesional y desarrollar habilidades de diálogo y acogida terapéutica, a través de actividades que facilitan la integración entre el contenido teórico y la propia experiencia.

Resultados: Al término del trabajo de taller, los alumnos expresan su valoración por esta forma de aprendizaje, reportando haber adquirido destrezas en el campo terapéutico y, al mismo tiempo, experimentado transformaciones en su vida personal.

Palabras clave: taller, habilidades interpersonales, habilidades psicoterapéuticas.
Workshop: "the therapist as a person":

A formative experience that enhances learning

Introduction: The ar ticle describes the activities of a workshop that addresses the therapist as a person, by way of developing int erpersonal skills in therapeutic work. This activity takes place during training of Psychological and Psychiatric trainees conduct ed in a P ediatric Hospital.

Methodology: The work is accomplished through the theoretical postulates of social constructionism, which integrates the ideas of post modern thought to social sciences and therapeutic practice. This ar ticle deals briefly with its main premises, which are studied in a parallel activity. The workshop utilizes experiential and interactive techniques to review personal issues, professional role and the development of dialogic and therapeutical skills. This work is achieved through activities that integrate theoretical content and personal experience.

Results: By the end of this workshop the students value this way of learning, reporting they have acquired therapeutical skills and, at the same time, experienced transformations in their personal lives.

Key words: workshop, therapeutic skills and interpersonal skills
Correspondencia:

Ana Margarita Maida Sosic

Unidad deTerapia Familiar, Depto. de Pediatría,

Campus Oriente, Universidad de Chile,

Hospital Luis Calvo Madkenna.

Antonio Varas 360, Providencia, Santiago, Chile.

Fono/Fax 56- 2- 2731415.

E-mail:mmaida@machi.med.uchile.cl

\section{INTRODUCCIÓN}

En el momento actual, el aprendizaje de la Medicina y de la Psicología está más centrados en aspectos técnicos que en la interacción entre el profesional y el cliente. Skelton y Hammond ${ }^{1}$ y Meryn ${ }^{2}$ 
opinan que a pesar de grandes avances tecnológicos en la calidad de la atención en salud, se ha agrandado la distancia entre el clínico y el paciente. Las relaciones se han hecho más impersonales y remotas, perdiéndose la capacidad de escuchar al otro. Los programas docentes de pre y post-grado en especialidades abocadas a la formación de terapeutas destinan espacios insuficientes al desarrollo de habilidades comunicacionales o de relaciones interpersonales.

Con el fin de responder a esta necesidad, en la Unidad de Terapia Familiar del Hospital Luis Calvo Mackenna, se realiza el taller "La persona del terapeuta" en el marco de un programa docente para egresados de Psicología y Psiquiatras en formación. El trabajo está dirigido a la revisión de aspectos personales y del rol de terapeuta con el fin de desarrollar una auténtica capacidad de escucha, mayor autoconocimiento en el plano de las relaciones interpersonales y mayor eficacia comunicacional. La metodología empleada es interactiva y experiencial, y se ha reunido una serie de técnicas que permiten dar a conocer el modelo teórico con el que el equipo de trabajo está comprometido, así como acceder a las situaciones que ocurren frecuentemente en la práctica profesional.

En los siete años en que se ha desarrollado esta experiencia, han participado 87 alumnos para quienes el taller ha resultado una actividad novedosa y útil en circunstancias que se aprestan a poner en práctica sus conocimientos y habilidades.

\section{MODELO TEÓR ICO}

El taller está guiado por las ideas del construccionismo social ${ }^{3,4}$, enfoque teórico que orienta la práctica psicoterapéutica que se realiza en la Unidad de Terapia Familiar. Los postulados no sólo hacen referencia a una forma de trabajo con las familias que se atienden, sino que tienen importantes connotaciones en ámbitos más amplios como la filosofía y la epistemología, por lo cual implican una revisión profunda de ideas y creencias no solo referidos al ámbito profesional, sino también personal y cultural. Es por ello que un aspecto central en la decisión de la metodología a utilizar, es que la forma en que se lleva a cabo y los resultados del taller estén en gran coherencia y sirvan para que los alumnos logren una comprensión experiencial, viviencial de los planteamientos filosóficos del enfoque. Este model o difiere de la psicología tradicional invitando a focalizar la atención desde el espacio intrapsíquico hacia el interaccional: los problemas que viven las personas y que llevan frecuentemente a terapia no están en el interior de la mente sino en lo complejo de las relaciones. Estas ideas teóricas se traducen en la práctica terapéutica en que tanto el proceso como los resultados son relacionales y que el rol del terapeuta está menos orientado hacia el diagnóstico y mucho más centrado en la generación de procesos sociales tales como el diálogo, lenguaje y significado. Sus postulados básicos son:

1. Postura crítica frente al conoci mi ento: Se desafía la noción que el conocimiento sobre los fenómenos sociales se adquiere de una observación objetiva de mundo y se cuestiona la idea de la existencia de realidades únicas. EI observador participa influyendo en el resultado de su observación y en consecuencia se apoya la noci ón de real idades construidas.

2. El conocimiento está inserto en un contexto histórico y cultural: Si la realidad no es única ni objetiva, las categorías y conceptos que usamos en el proceso de conocer dependen decircunstancias históricas y culturales. U n ejempl o podría ser la noción de homosexualidad, la que ha experimentado cambios a lo largo de la historia, desde ser considerada un deli to, a una patología, a una vari ación de la normal idad. 3. E I conocimiento se construye en el espacio social:_El conocimiento no se produce en el "interior" delas personas, sino que se genera en la interacción, en $\mathrm{d}$ intercambio social. El lenguaje toma un rol preponderante en la construcción de ideas y creencias.

\section{Cada construcción invita a una acción: Las} ideas y discursos a los cuales adhieren las personas sustentan su actuar. Así, por ejemplo, frente a un niño que tiene bajo rendimiento escolar, las acciones a tomar van a depender de las creencias. Si se lo consider a "discapacitado", probablemente se le exi girá poco y se evitará que sufra; si se lo ore "mimado", la exigencia va a aumentar; si se piensa que es "manipulador", tal vez se ađúe con rabia y se le exija más allá de lo queel propio niño sesienta capaz. De esta forma las descripciones o construcciones del mundo sostienen algunos patrones de acción y exduyen otros.

\section{La identidad se expresa y se desarrolla a tra-} vés de narraciones: De acuerdo a esta visión, la idea que las personas tienen acerca desi mi smas está contenida en relatos o narraci ones, las que están en per manente modificación. Cada nueva versión de un relato permite que las personas re-escriban su historia, la que incluye la anterior y la amplía, transformando así su mundo per sonal y sus relaciones ${ }^{5,6}$. Un relato o nar ración nunca abarcará toda la riqueza de 
la experiencia. Cada persona elabora un relato "dominante" de su vida, quedando fuer a contenidos que no confirman esa versión original. Incorporar estos contenidos marginales permite, muchas veces, elaborar otros relatos, o ampliar los que se habían vuel to par a la persona al go que limita sus posibilidades y provoca sufrimi ento.

\section{OBJETIVOS DEL TALLER "LA PERSONA DEL TERAPEUTA"}

- Revisar aspectos relacionados con el rol de terapeuta para desarrollar habilidades de escucha y comprensión de los problemas de las familias y las personas con que trabajan en terapia.

- Desarrollar habilidades para generar diálogo terapéutico.

- Proporcionar un espacio para que el alumno en formación explore las repercusiones personales de los problemas que se presentan en terapia y en el trabajo en equipo.

- Generar aprendizaje a través de una experiencia reflexiva y vivencial en torno a los postulados del Construccionismo Social

\section{ESTRUCTURA DEL TALLER}

El taller se realiza por espacio de 9 meses, una vez por semana, con una duración de 3 horas. Suele contar con la participación de 9-12 alumnos y dos conductores. El rol de estos últimos es escuchar y, a partir del diálogo que va surgiendo con los alumnos, proponer actividades en cada sesión. Se genera un ambiente de trabajo colaborativo, en que todo el equipo comparte el proceso de aprendizaje.

Entre un sinnúmero de técnicas de trabajo experiencial e interactivo, para este taller se han escogido algunas que a juicio del equipo docente respetan y permiten ilustrar las principales premisas del construccionismo social.

El taller no es una experiencia de terapia personal. Cada participante se compromete en forma libre y aporta experiencias personales en la medida en que está dispuesto, lo que es respetado por los conductores.

\section{ACTIVIDADES}

\section{Genograma:}

El genograma7 consiste en el relato de la familia de origen. En esta actividad cada alumno expone al grupo la historia de tres generaciones de su familia y los conductores van graficando este relato en una pizarra. Se anota la edad, sexo y actividades de los integrantes de la familia. En la presentación del genograma se produce un diálogo entre los supervisores y el alumno, en el que se buscan significados asociados a las palabras que utiliza, a las historias que narra y los acontecimientos que destaca, a los contenidos valóricos transmitidos de generación en generación.

Se exploran las creencias de la familia, cómo fueron construidas y cómo estas influyen en la construcción de la historia de vida del alumno. Se destacan antecedentes étnicos, geográficos, culturales, políticos, profesionales, de género, accidentes biográficos, etc. A través del diálogo se va revisando esta narrativa, se la cuestiona o se la amplía, pudiendo surgir nuevas comprensiones. De esta manera se va abriendo la posibilidad de incorporar otras ideas, fortalezas, lazos de afecto, lecturas distintas a las que han predominado hasta el momento y que han podido significar límites o sufrimiento.

En una ocasión, un participante relató que su abuela había enviudado joven debiendo trabajar para hacerse cargo de sus hijos pequeños. El alumno relataba que su padre se había sentido descuidado por su madre. La historia familiar, en la narración del participante, excluía el esfuerzo realizado por la abuela ante la necesidad de alimentar a sus hijos. A raíz de esta experiencia, más adelante en el año, el alumno relató que había empezado a considerar de otra manera el significado del trabajo femenino.

Estos ejercicios tienen una doble repercusión para los alumnos. Una, por la revisión de su propia historia, y otra, en el rol que desempeña como psicoterapeuta y participante de un diálogo en el cual la historia y los relatos pueden ser cuestionados. EI ser testigo de otros relatos y participar en la búsqueda de nuevos significados, permite ejercitar capacidades de comprensión y ampliar perspectivas. Si un terapeuta aprende que puede hacer cambios en la forma de ver a su propia familia, también puede aceptar la idea que otros hagan cambios en la forma de ver sus historias.

Una actividad que complementa el ejercicio de genograma es el escudo de familia ${ }^{8}$, el que consiste en una expresión gráfica de temas relevantes de la vida familiar. La idea es que el alumno delinee una forma sugerente de escudo y dibuje en su interior objetos o símbolos de contenidos que considera más relevantes y representativos. Este trabajo permite obtener un panorama de vivencias, emociones, valo- 
res y creencias que la persona percibe como heredados de su familia y que lleva consigo para enfrentar la vida.

\section{2.- J uego de roles:}

En el juego de roles $^{9}$ se exploran múltiples posturas vitales actuando, sintiendo y pensando como si se fuera otra persona. En la primera etapa de la práctica clínica, esta técnica permite ensayar habilidades básicas para hacer preguntas, escuchar y reconocer aperturas en el diálogo que llevan a nuevos temas.

Esta técnica es útil también para revisar dificultades surgidas en el trabajo terapéutico. Con este ejercicio el alumno puede re-pensar y re-actuar situaciones ya vividas en sesión, con clientes simulados que a su vez le entregan comentarios de sus propias conductas y reacciones frente a la relación terapéutica que se ha establecido.

En una ocasión se escenificó a una familia en que la madre y los hijos esperaban muchos cambios de parte del padre, quien no parecía dispuesto a ello, generando actitudes negativas en los hijos. Un participante que desempeñaba el rol de terapeuta, manifestó que no podía trabajar con una familia donde no se respetaba al padre. En su familia, esta era una figura muy valorada. Con este ejercicio, el alumno reconoció que esta idea, aún siendo positiva, podía convertirse en un prejuicio que afectara su relación terapéutica.

\section{Escultura:}

La escultura ${ }^{9}$ es una forma de relato, en la cual el escultor comunica, a través de su creación, la situación que vive o lo aproblema. Esta consiste en representar una familia, un momento vital, una situación surgida en terapia, utilizando a personas del grupo, ubicándolos espacialmente y moldeando sus gestos y expresiones como un escultor que da vida a la arciIla. Luego, el escultor y los observadores analizan los temas sugeridos al observar la obra.

Las personas "esculpidas", desde el rol o personaje asignado por el escultor, comentan sus percepciones y sensaciones, expresan deseos y plantean preguntas al escultor, quien recibe estas opiniones y participa en una nueva reflexión. Este ejercicio ofrece a quien actúa como escultor, ideas, creencias y sentimi entos que pueden estar inter viniendo en la situación queinspi rósu escultura y queél no ha considerado. Surgen así aspectos novedosos que pueden ofr ecer alternativas a si tuaciones aparentemente sin salida. Se potencia la idea que los atascamientos en terapi a tienen que ver con las propias visiones y no con una situación externa determinada.
La escultura aúna creatividad y simbolismo, permite crear y observar formas alternativas de relatos, empleando distintos códigos: visuales, kinestési cos, emocionales, simbólicos. El lenguaje se convierte en acción, cuya expresión da lugar a nuevas conversaciones.

\section{4.- Equipo reflexivo:}

Esta modalidad de trabajo para la práctica y el entrenamiento en terapia ha sido introducida por Andersen ${ }^{10}$. El equipo reflexivo consiste en observar y escuchar atentamente un diálogo determinado, por ejemplo, una sesión de terapia. Luego quienes dial ogan (Ilamado "sistema participante") hacen una pausa para escuchar a quienes antes observaban y escuchaban. El equipo reflexivo comparte ideas, preguntas y observaciones referidas a lo observado y escuchado del sistema participante. Cada miembro del equipo comenta en primera persona, sin hacer interpretaciones y cuidando ser respetuoso con quienes escuchan.

En un tercer tiempo, el sistema participante tiene la oportunidad de comunicar e intercambiar sus reflexiones en torno a lo dicho por el equipo reflexivo. Ellos pueden acoger o no las reflexiones, darles sentido a unas y noa otras, integrarlas a sus propios relatos devida o desechar las totalmente. Esta forma detrabajo pretende facilitar que surja un abanico de visiones, queson presentadas a la familia consultante o al terapeuta en entrenami ento, sin exclusiones.

Esta actividad se realiza en el taller para supervi sar casos concretos, para complementar un role playing de una situadión terapéutica o para refl exionar en torno a un genograma. En la docencia, este trabajo permite desarr ollar las habilidades de reflexión. A su vez, los al umnos aprenden a generar i deas que no necesari amenter esponden a visiones únicas ni a gener al izaciones sobre los temas tratados.

\section{5.- Múltiples voces:}

Este es un ejercicio adaptado del trabajo que Harlene Anderson ${ }^{5}$ denomina "como si". En este se pone de relieve la multiplicidad y complejidad de toda experiencia humana, tomando en cuenta que la narrativa de una persona frente a una situación determinada, está construida a partir de los múltiples diálogos en que ella participa.

Un integrante del grupo presenta un problema sobre el que quiere trabajar. Este será analizado desde todas las perspectivas posibles según el número de actores que estén involucrados. Se instruye a los alumnos que cada uno escuche el relato desde la perspectiva de un personaje particular. Al terminar la narración, cada uno ofrece su reflexión. 
Esta modalidad de trabajo permite una comprensión más amplia de las situaciones vitales. Por ejemplo la visión de un padre puede ser muy diferente de la de un hijo y ambos diferir de la visión de la profesora. Las tres visiones, con sus diferencias, incluso con su oposición, enriquecen la visión global de la situación en cuestión. A través del ejercicio los alumnos experimentan la riqueza de las diferentes voces, reconociendo aspectos que pueden haber estado excluidos de los relatos y aceptando ideas que pueden ser contradictorias o disonantes, frente a una misma situación.

\section{CONCLUSIONES}

El trabajo que se realiza con futuros terapeutas en el Taller "La persona del terapeuta" resulta nove doso por el énfasis dado a los aspectos personales y de la relación entre profesional y cliente, los cuales no suelen recibir suficiente atención en los programas de formación terapéutica.

El trabajo experiencial como una metodología interactiva ofrece ventajas en cuanto a que permite demostrar "lo que no puede ser daramente descrito"n. Entre los aspectos más centrales del taller está la contribución a la docencia que brinda esta forma de aprender.

Al término de cada taller, los participantes realizan una evaluación verbal del propio proceso de aprendizaje, manifestando un alto grado de satisfacción con esta experiencia. A través del vivenciar y participar activamente, ellos reconocen que van integrando los contenidos teóricos a la práctica del diálogo terapéutico. Destacan la posibilidad de experimentar personalmente cómo se conoce y escucha, además de apreciar cómo conocen otros y cuán diversas pueden ser las visiones de lo que se llama "realidad".
Asimismo, los alumnos expresan su valoración por esta forma de aprendizaje, reportando haber adquirido destrezas en el campo terapéutico $y$, al mismo tiempo, experimentado transformaciones en su vida personal.

Es probable que el éxito del taller también se explique por la disposición de los participantes a comprometerse en las actividades propuestas, quedando de manifiesto que aquellos que se exponen más personalmente, obtienen más beneficios.

Wall ${ }^{12}$ destaca el consejo educativo que entrega un antiguo proverbio chino:

\section{Escucho y olvido, Veo y recuerdo, Hago y enti endo.}

\section{BIBLIOGRAFÍA}

1. Skelton, J ., Hammond, P. Medical Teacher, Vol. 20, N 6, 1998.

2. Meryn, S. Improving communication skills: to carry coals to Newcastle? Medical Teacher, Vol. $20 \mathrm{~N}^{\circ} 4,1998$.

3. Burr, V. An introduction to Social Constructionism. Routledge. London and New York. 1999.

4. McNamee, S., Gergen, K. La terapia como construcción social. Paidos. 1995.

5. Anderson, H. Conversation, language and possibilities. A postmodern approach to therapy. Basic Books. 1997.

6. White, M., Epston, D. Narrative means to Therapeutic Ends. W.W. Norton \& Company. New York. 1990.

7. McGoldrick, M., Gerson, R. Genogramas en la evaluación familiar. Gedisa. 1987.

8. Troya, E. Comunicación personal en taller dedicado a la persona del terapeuta. Instituto Chileno de Terapia Familiar. 1994.

9. Stratton, P. Preston-Shoot M., Hanks H. Family Therapy. Training and Practice. Venture Press. 1990.

10. Andersen, T. EI equipo reflexivo. Diálogos y diálogos sobre los diálogos. Gedisa. 1994.

11. Wall, D. Twelve tips on teaching teachers to teach. Medical Teacher, Vol. 21, N4, 1999 